\title{
PRVI NALAZ BRIJESTOVE OSE LISTARICE (Aproceros leucopoda) U BOSNI I HERCEGOVINI
}

\section{FIRST RECORD OF ELM SAWFLY (Aproceros leucopoda) IN BOSNIA AND HERZEGOVINA}

\author{
Mirza DAUTBAŠIĆ ${ }^{1}$, Osman MUJEZINOVIĆ ${ }^{1}$, Kenan ZAHIROVIĆ² , Josip MARGALETIĆ
}

\begin{abstract}
Sažetak
Brijestova osa listarica je invazivni štetnik, podrijetlom iz Japana i Kine. Unesena je u Europu posredstvom egzotičnih vrsta brijesta. U Bosni i Hercegovini je prvi puta otkrivena ovim nalazom 2017. godine na području općine Vareš na nekoliko lokaliteta. Ni na jednom od lokaliteta štetnik nije uzrokovao značajniju defolijaciju. Budući da je ovo strana i potencijalno invazivna vrsta, može se očekivati njeno širenje po čitavom području Bosne i Hercegovine.
\end{abstract}

KLJUČNE RIJEČI: brijest, osa listarica, invazivna vrsta, Vareš.

\section{UVOD}

\section{INTRODUCTION}

Uslijed sve većeg uvoza sadnog materijala, nedovoljno dobre kontrole, dolazi često do introdukcije štetnih organizama, koji su za određena podneblja i vrste drveća i grmlja do tada bili nepoznati (Glavendekić i dr., 2013). Prema Roques i dr. (2009) godišnje se u Europu unese u prosjeku 17,5 novih vrsta insekata. U proteklih nekoliko godina u Bosnu i Hercegovinu je uneseno nekoliko štetnika (Leptoglossus occidentalis, Arge berberidis, Pontania viminalis, Obolodiplosis robiniae, Oxycarenus lavaterae itd.) (Dautbašić i Mujezinović, 2016).

Brijestova osa listarica Aproceros leucopoda (Hymenoptera, Argidae) je 2003. godine introducirana u Europu (Zandi- giacomo i dr., 2011; Matošević, 2012; Zúbrik i dr., 2013; Blank i dr., 2014; Doychev, 2015; Hausl-Hofstätter i Höllriegl, 2015; Vétek i dr., 2016). Utvrđena je na nekoliko vrsta brijestova, od kojih su najvažniji gorski brijest (Ulmus glabra Huds.) i nizinski brijest (Ulmus minor Mill.) (Matošević, 2012; Glavendekić i dr., 2013). Prirodno rasprostranjenje štetnika osiguravaju odrasle ženke, pri čemu se u prosjeku godišnje šire $45-90 \mathrm{~km}$ (EPPO, 2015). Cilj ovoga rada bilo je utvrđivanje nazočnosti brijestove ose listarice morfološkim putem na istraživanom lokalitetu.

A. leucopoda ima i do četiri generacije godišnje, razmnožava se partenogenetski, što nije utvrđivano ovim radom (Pricop i dr., 2012; Matošević, 2012; Zúbrik i dr., 2013; Blank i dr., 2014; Hausl-Hofstätter i Höllriegl, 2015; Vétek

\footnotetext{
1 prof. dr. sc. Mirza Dautbašić, Šumarski fakultet Univerziteta u Sarajevu, Katedra za zaštitu šuma, urbanog zelenila i lovnog gospodarenja, Zagrebačka 20, 71000 Sarajevo, Bosna i Hercegovina, e-mail:mirzad@bih.net.ba

'prof. dr. sc. Osman Mujezinović, Šumarski fakultet Univerziteta u Sarajevu, Katedra za zaštitu šuma, urbanog zelenila i lovnog gospodarenja, Zagrebačka 20, 71000 Sarajevo, Bosna i Hercegovina, e-mail: osmansfs@yahoo.com

${ }^{2}$ Dr. sc. Kenan Zahirović, JP Šumsko-privredno društvo Zeničko-dobojskog kantona d.o.o Zavidovići, Alije lzetbegovića 25, 72220 Zavidovići, Bosna i Hercegovina, e-mail: zahirovic_kenan@yahoo.com

${ }^{3}$ prof. dr. sc. Josip Margaletić, Šumarski fakultet Sveučilišta u Zagrebu, Zavod za zaštitu šuma i lovstvo, Svetošimunska cesta 25, 10000 Zagreb, Hrvatska, e-mail: josip.margaletic@sumfak.hr
} 
Tablica 1. Lokaliteti prvog nalaza brijestove ose listarice u Bosni i Hercegovini

Table 1. Localities of first record of elm sawfly in Bosnia and Herzegovina

$\begin{array}{ccc}\text { Datum - Date } & \text { Lokalitet - Locality } & \text { Koordinate - Coordinates } \\ \text { 27.06.2017. } & \text { Ponikva } & 44^{\circ} 10^{\prime} 25^{\prime \prime} \mathrm{N} ; 18^{\circ} 22^{\prime} 30^{\prime \prime} \mathrm{E} \\ 27.06 .2017 . & \text { Predvojnički } & 44^{\circ} 10^{\prime} 22^{\prime \prime} \mathrm{N} ; 18^{\circ} 22^{\prime} 55^{\prime \prime} \mathrm{E} \\ 27.06 .2017 . & \text { Šimin potok } & 44^{\circ} 10^{\prime} 28^{\prime \prime} \mathrm{N} ; 18^{\circ} 24^{\prime} 14^{\prime \prime} \mathrm{E} \\ 28.06 .2017 . & \text { Osoje } & 44^{\circ} 10^{\prime} 37^{\prime \prime} \mathrm{N} ; 18^{\circ} 20^{\prime} 56^{\prime \prime} \mathrm{E}\end{array}$

i dr., 2016). Štetnost se ogleda u brstu listova brijesta, gdje u nekim slučajevima dolazi i do njihovog potpunog skeletiranja (Blank i dr., 2010; Zandigiacomo i dr., 2011; Doychev, 2015).

\section{MATERIJAL I METODE MATERIALS AND METHODS}

Rekognosticiranjem terena u srpnju 2017. godine u Bosni i Hercegovini na stablima gorskog brijesta (Ulmus glabra), utvrđeni su karakteristični simptomi žderanja (cik-cak obrazac), prisutnost ličinki i imaga. Istraživanja su provedena na ukupno četiri lokaliteta na području središnje Bosne (tablica 1). Ličinke i imaga s lokaliteta istraživanja sakupljeni su i pohranjeni u 75\% etanol, radi kasnijih morfoloških analiza. Determinacija štetnika izvršena je u laboratoriju Katedre za zaštitu šuma i urbanog zelenila Šumarskog fakulteta Univerziteta u Sarajevu. Ista je provedena po ključu Blank i dr. (2010) na temelju razvojnih stadijuma imaga, ličinke i obrazca žderanja ličinke, koji su fotografirani prenosnim mikroskopom SVP DM540. Nakon provedenih morfoloških analiza primjerci štetnika pohranjeni su u hladnjaku. Ovim istraživanjem nije proučavana biologija ove vrste.

\section{REZULTATI}

\section{RESULTS}

Brijestova osa listarica prvi puta je otkrivena u Bosni i Hercegovini na gorskom brijestu 27. 06. 2017. godine na lokalitetu Ponikva, općina Vareš. Daljnjim pregledom štetnik je utvrđen na još tri lokaliteta.
Utvrđene štete na listovima bile su vidljive samo kao izgrižene cik-cak linije, te nisu utvrđeni potpuno obršteni listovi. $\mathrm{Na}$ dijelu napadnutih listova (slika 1) vidljivo je karakteristično cik-cak žderanje ličinki, te sama ličinka (slika 2). Pregledom gornje strane lista utvrđena je i prisutnost ženke brijestove ose listarice (slika 3). Ni na jednom lokalitetu nije nastala djelomična ili potpuna defolijacija listova.

\section{ZAKLJUČCI CONCLUSIONS}

Na osnovi prvog nalaza brijestove ose listarice može se zaključiti sljedeće:

- Štetnik je u Bosnu i Hercegovinu najvjerojatnije došao prirodnim rasprostranjenjem, nakon što je 2011. i 2012. godine otkriven na području Hrvatske i Srbije;

- Nađene su ličinke i imaga brijestove ose listarice, te utvrđen karakterističan obrazac žderanja ličinki na listu gorskog brijesta;

- Potrebna su dodatna istraživanja biologije, štetnosti i širenja štetnika na stablima brijesta u Bosni i Hercegovini i

- Značaj otkrivanja stranih vrsta na novom području, a samim tim i na području Bosne i Hercegovine, ogleda se u potrebi za planiranjem svih zaštitnih mjera u oblasti šumarstva.

\section{LITERATURA}

REFERENCES

- Blank, S. M., Hara, H., Mikulás, J., Csóka, Gy., Ciornei, C., Constantineanu, R., Con-stantineanu, I., Roller, L., Altenhofer, E., Huflejt, T., Vétek, G. (2010): Aproceros leucopoda (Hymenoptera: Argidae): An East Asian pest of elms (Ulmus spp.) invading Europe. European Journal of Entomology, 107: 357-367.

- Blank, S. M., Hara, H., Mikulás, J., Csóka, G., Ciornei, C., Constantineanu, R., Constantineanu, I., Roller, L., Altehofer, E., Huflejt, T., Vétek, G. (2010): Aproceros leucopoda (Hymenoptera: Argidae): An East Asian pest of elms (Ulmus spp.) invading Europe. Eur. J. Entomol. 107: 357-367.
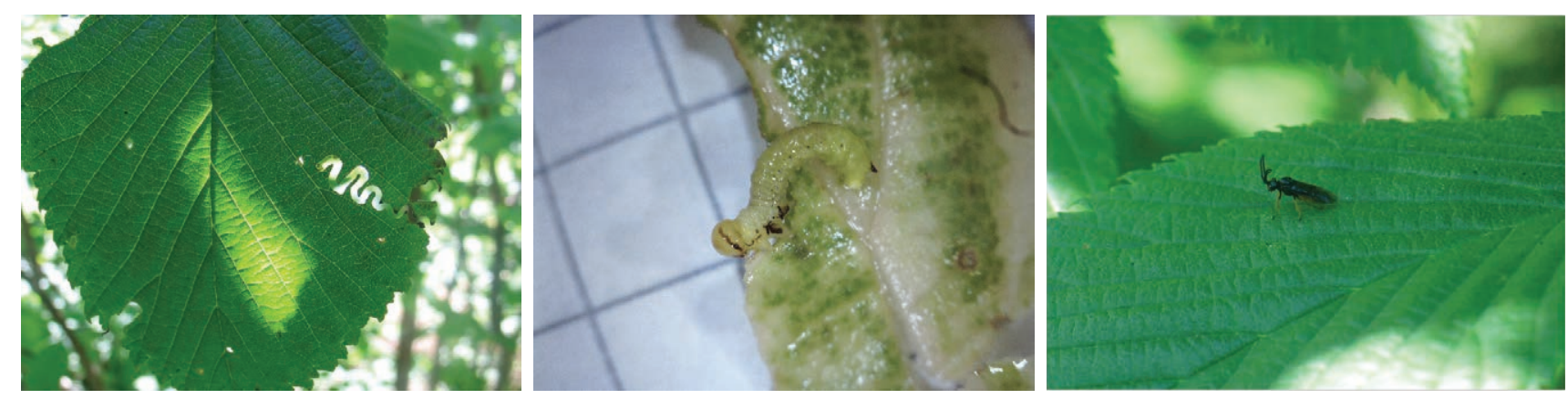

Slika 1, 2 i 3. Karakteristično cik-cak žderanje ličinki, ličinka i ženka štetnika Aproceros leucopoda

Picture 1, 2 and 3. Characteristic zig-zag defoliation of larvae, larvae and adult female of pest Aproceros leucopoda 
- Constantineanu, R., Blank, S. M., Köhler, T., Pfannenstill, T., Neuenfeldt, N., Zimmer, B., Jansen, E., Taeger, A., Liston, A. D. (2014): Zig-zagging across Central Europe: recent range extension, dispersal speed and larval hosts of Aproceros leucopoda (Hymenoptera, Argidae) in Germany. Journal of Hymenoptera Research 41. str. 57-74.

- Dautbašić, M., Mujezinović, O. (2016): Pregled novootkrivenih štetnika u šumama i na hortikulturnim biljkama u Bosni i Hercegovini. 60. Seminar biljne zaštite, Opatija.

- Doychev, D. (2015): First Record of Invasive Elm Sawfly Aproceros leucopoda Takeuchi (Hymenoptera: Argidae) in Bulgaria. Silva Balcanica 16(1). Str. 108 - 112.

- EPPO (2015): Aproceros leucopoda (Hymenoptera: Argidae Zigzag elm sawfly). str. 1 - 3.

- Glavendekić, M., Petrović, J., Petaković, M. (2013): Strana invazivna vrsta Aproceros leucopoda Takeuchi (Hymenoptera: Argidae) - štetočina brestova u Srbiji. Šumarstvo 1 - 2. str. 57-66.

- Hausl-Hofstätter, U., Höllriegl, R. (2015): Die Zick-Zack-Ulmenblattwespe Aproceros leucopoda Takeuchi, 1939 nun auch in der Steiermark und im Burgenland (Hymenoptera, Argidae). Joannea Zoologie 14: str. 59-63.
- Matošević, D. (2012): First record of elm sawfly (Aproceros leucopoda), new invasive species in Croatia. Šumarski list 136(1/2). str. 57-61.

- Pricop, E., Cardaş, G., Ciornei, C., Andriescu, I. (2012): On the egg parasitoids of Aproceros leucopoda (Hymenoptera: Argidae), an invasive pest species from Japan. Animal Biology \& Animal Husbandry International Journal of the Bioflux Society. str. 43 $-46$.

- Roques, A., Rabitsch, W., Rasplus, J.Y., Lopez-Vaamonde, C., Nentwig, W., Kenis, M. (2009): Alien terrestrial invertebrates of Europe. The Handbook of Alien Species in Europe, 63-79.

- Vétek, G., Papp, V., Fail, J., Ladányi, M., Blank, S.M. (2016): Applicability of Coloured Traps for the Monitoring of the Invasive Zigzag Elm Sawfly Aproceros leucopoda (Hymenoptera: Argidae). Acta Zoologica Academiae Scientiarum Hungaricae 62(2), pp. 165-173.

- Zandigiacomo, P., Cargnus, E., Villani, A. (2011): First record of the invasive sawfly Aproceros leucopoda infesting elms in Italy. Bulletin of Insectology 64 (1). str. 145-149.

- Zúbrik, M., Kunca, A., Csóka, G. (2013): Insects and Diseases Damaging Trees of Europe. N.A.P. Éditions. A colour atlas. str. $1-535$.

\section{Summary}

The invasive species was first discovered in 2017 year in Bosnia and Herzegovina, Vareš municipality, on trees of mountain elm. It was not researched biology of pest. It was discovered characteristic zigzag defoliation of larvae, and found female adult. No partial or full defoliation caused by this pest was found, and the defoliation was determined on individual leaves. It is needed further researchs on the biology, harm and spread of pest on elm in Bosnia and Herzegovina.

KEY WORDS: elm, sawfly, invasive species, Vareš. 